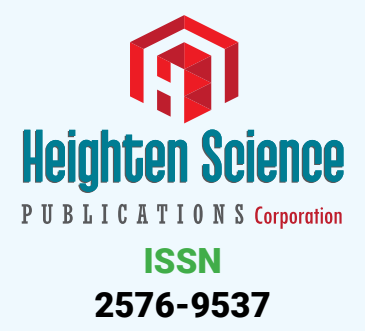

*Address for Correspondence: Safi Khuri, General Surgery Department, Rambam Health Care Campus, Haifa, Israel, Tel: 00972502062169; 00972525989342; Email: s_khuri@rambam.health.gov.il

Submitted: 21 May 2019

Approved: 31 May 2019

Published: 03 June 2019

Copyright: (c) 2019 Mansour S, et al. This is an open access article distributed under the Creative Commons Attribution License, which permits unrestricted use, distribution, and reproduction in any medium, provided the original work is properly cited

Check for updates

\section{Massive gastrointestinal bleeding; never too old to be due to Meckel's Diverticulum - A case report and literature review}

\author{
Subhi Mansour ${ }^{1}$, Kenan Halloun ${ }^{1}$ and Safi Khuri ${ }^{1,2 *}$ \\ ${ }^{1}$ General Surgery Department, Rambam Health Care Campus, Haifa, Israel \\ ${ }^{2} \mathrm{HPB}$ and Surgical Oncology Unit, Rambam Health Care Campus, Haifa, Israel
}

\section{Abstract}

Gastrointestinal ( $\mathrm{GI}$ ) bleeding is a very common medical problem encountered in the acute care setting, and is a major cause of admission to hospitals with about 300,000 patients admitted annually. Obscure $\mathrm{GI}$ bleeding, defined as persistent or recurrent bleeding following initial negative upper and lower endoscopy, represents approximately $5 \%$ of all GI hemorrhages. The small bowel is the most common source for obscure GI bleeding. Variable lesions of the small bowel can cause obscure GI bleeding, with tumors, Crohn's disease and Meckel's diverticulum being more common in young age group. Meckel's diverticulum, the most common $\mathrm{Gl}$ congenital malformation, is usually asymptomatic and incidentally found. It can present with Gl bleeding, seen more in pediatric patients, and rarely in adult patients. Herein, we present a 45 years old female patient, presenting with massive obscure GI bleeding due to Meckel's diveticulum.

\section{Introduction}

Gastrointestinal (GI) hemorrhage is a very common surgical problem, with an estimated incidence rate of 150 patients / 100,000 populations and a mortality rate of $5-10 \%[1,2]$. GI bleeding can be defined as overt, when the bleeding is obvious to the treating physician, or occult, which usually presents as a hemoccult-positive stool, with or without iron deficiency anemia [3,4]. Obscure GI bleeding, which represents almost $5 \%$ of all GI hemorrhage, is defined as a recurrent or persistent bleeding following negative upper and lower endoscopy and radiologic imaging of the small bowel. Small bowel bleeding is usually the most common cause of obscure GI bleeding at $41-75 \%$ $[5,6]$.

Several lesions of the small bowel can present with GI hemorrhage, the most common cause for the hemorrhage differs within different age groups [7]. In patients younger than 40 years of age, the most common causes for hemorrhage originating in the small bowel are primary or secondary tumors, Crohn's disease and Meckel's diverticulum, while vascular lesions and Non-steroidal anti-inflammatory (NSAIDs) drugs related lesions are the most causes in the elderly age group (older than 40 years of age) $[5,8]$.

Meckel's diverticulum is the most common congenital malformation of the GI tract, and is encountered more in pediatric surgical patients than in adult patients [9]. It is the result of persistent remnant of the omphalomesentric duct, and usually located on the antimesentric side of the distal ileum. The reported incidence of such rare 
entity is $2 \%$ of the general population. Although it can present as a gastrointestinal hemorrhage, diverticulitis or intestinal obstruction, the most common presentation is incidental finding during operation $[10,11]$. It is twice more common in males than in females, and in $10-20 \%$ of cases, an ectopic abnormal tissue (mostly gastric), can be found. In most cases, Meckel's diverticulum is found within a $100 \mathrm{~cm}$ from the iliocecal valve [12].

Due to it being an embryological remnant (unlike other diverticulas in the GI tract), it presents as a blind recess on the anti-mesenteric border of the ilium [13]. Usually, complications are reported more in male patients than in female patients [14].

The overall lifetime risk of developing Meckel's related complications varies in the medical literature between 4 to 40 percent [15], with the most common being hemorrhage, intestinal obstruction and diverticulitis. Other rare complications include intussusception, hernia torsion, umbilical sinus or fistula and neoplasm [16].

Among symptomatic patients, GI hemorrhage is the most common symptom, observed more in pediatric patients and relatively less in adults [17]. The bleeding is almost always due to peptic ulceration of the contralateral bowel wall [18]. For intermittent or occult bleeding, an arteriography can detect the origin of the bleeding [19].

The maximal probability of onset of complications is prior to two years of age, progressively decreasing to approximately none after 70 years of age [20]. The incidence of complications drops to nearly $1 \%$ around the age of 40 [21].

We hereby present a case of a massive obscure GI bleeding in a 45-year-old woman due to Meckel's diverticulum, which was detected during diagnostic laparoscopy, following negative complete diagnostic work up for GI hemorrhage.

\section{Case Presentation}

A 45-year-old female patient, who is known to suffer from Diabetes Mellitus and Hyperlipidemia, presented to our emergency room department with dark tarry stool of two weeks' duration which turned to bloody stool on the same day of admission. She also complained about general weakness and dizziness. Due to the aforementioned complaints, she was treated by her family physician with iron tablets supplements. On physical examination upon her admission, she looked pale, her vital signs were within normal limits. Abdominal examination revealed a soft and lax abdomen without tenderness, no palpable masses were detected. Digital rectal exam was consistent with dark cherry red stool, without palpable masses. Complete blood count showed very low hemoglobin level of $4.3 \mathrm{~g} / \mathrm{dL}$ and normal white blood cell count. Liver and kidney function tests were within normal limits. A short rigid colonoscopy revealed cherry red stool mixed with melena without obvious bleeding source. A nasogastric tube showed bilious secretions. Two packed cells were transfused, and the patient was admitted with a diagnosis of lower gastrointestinal bleeding for further treatment and investigations.

Upon her admission, a repeated complete blood count revealed hemoglobin levels of $6.4 \mathrm{~g} / \mathrm{dl}$, and two further packed cells were transfused.

During her hospitalization, the patient underwent a complete test panel to determine the source of the hemorrhage. Upper endoscopy was normal and lower endoscopy showed melena along the whole length of the colon without determining the source of bleeding. A Computed Tomographic Angiography (CTA) was normal without contrast blush or suspected space occupying lesions. Capsule endoscopy, as well as double balloon endoscopy were also normal without abnormal pathological findings. Red blood cell (RBC) scan was positive and demonstrated an intermittent blood pool in the right lower quadrant of the abdomen (Figure 1). 
Throughout her admittance period, she was treated with nine units of red blood cells and three units of fresh frozen plasma. However, repeated hemoglobin levels showed evidence of persistent bleeding, and repeated digital rectal exams showed a cherry red stool.

Due to continuous clinical gastrointestinal bleeding, along with the findings previously mentioned in the RBCs scan, the patient underwent a diagnostic laparoscopy.

During the operation, an $8 \mathrm{~cm}$ longitudinal tubular mass protruding from the terminal ilium, $50 \mathrm{~cm}$ from the ileo-cecal valve, similar in its characteristics to a Meckel's diverticulae, was demonstrated (Figure 2). En block resection of the diverticulae along with a $20 \mathrm{~cm}$ segment of small bowel and a primary hand sewn anastomosis was completed. Upon opening the resected segment, an ulcer was observed on the contralateral wall of the diverticulae (Figure 3). Her post-operative period was uneventful, and she was discharged on post-operative day 5 .

The histopathological report was compatible with Meckel's diverticula with hyperplastic gastric mucosa.

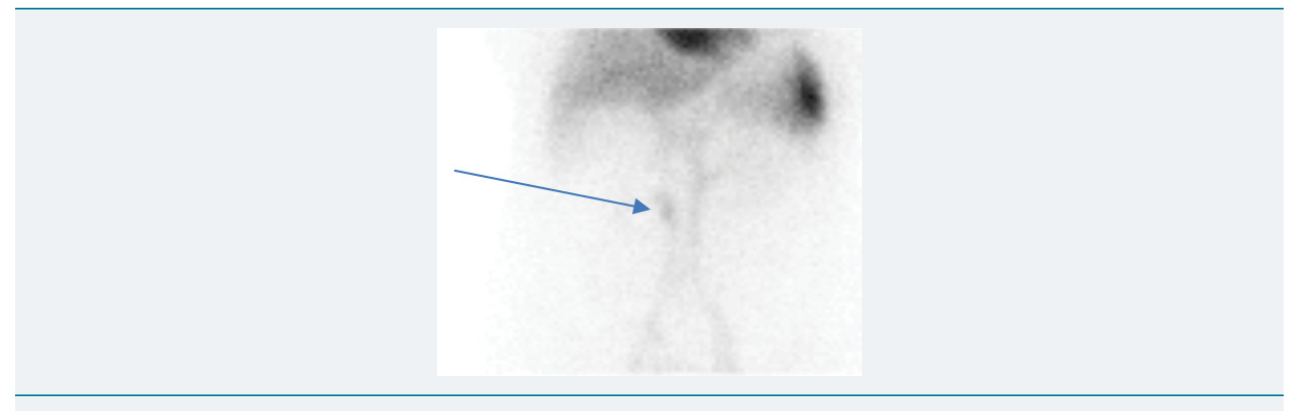

Figure 1: Red blood cell (RBC) scan demonstrating an intermittent blood pool in the right lower quadrant of the abdomen (arrow).

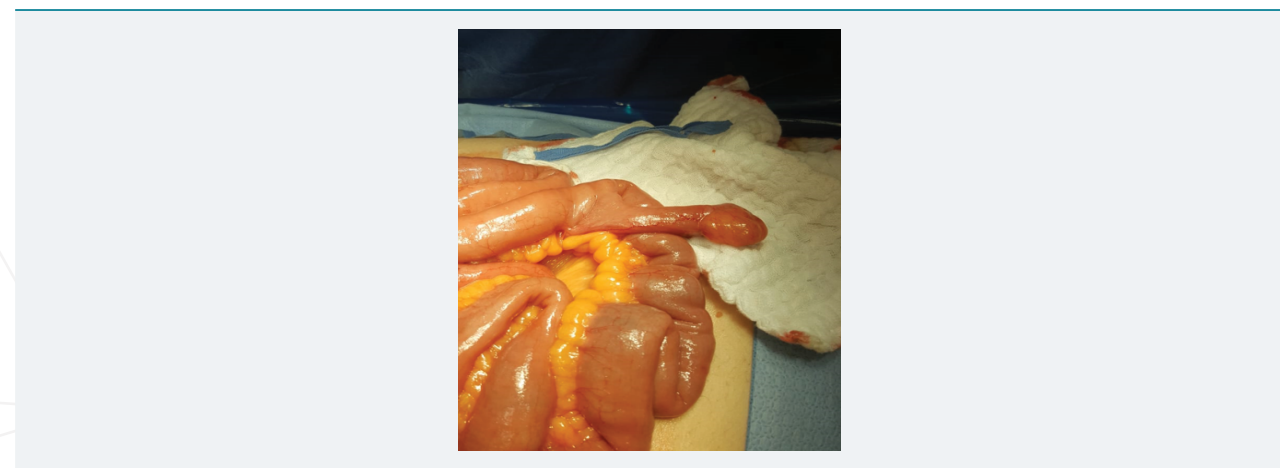

Figure 2: During operation, an $8 \mathrm{~cm}$ longitudinal tubular mass protruding from the terminal ileum, $50 \mathrm{~cm}$ from the ileo-cecal valve, suspected for Meckel's diverticula was demonstrated.

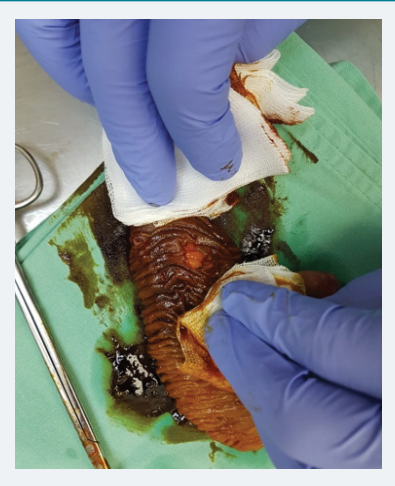

Figure 3: Upon opening the resected segment, an ulcer was observed on the contralateral wall of the diverticula 


\section{Discussion}

Meckel's diverticulum, which develops due to congenital vitellointestinal tract persistence, is the most common small intestinal congenital malformation [10]. It was described in 1809 by the German anatomist Johann Meckel, and frequently known by the rule of two, as it is present in $2 \%$ of the population, located 2 feet proximal to the ileo-cecal valve, it's length is almost 2 inches, and can include two ectopic tissues (gastric or pancreatic).

Although it is usually asymptomatic, it can present with abdominal pain due to intestinal obstruction or acute diverticulitis, or in the form of obscure GI bleeding [22]. The most common complications in adult patients are intestinal obstruction and diverticulitis. The risk of complications usually decreases with increasing age, and there are no predictive factors to anticipate complications of Meckel's diverticulum [22].

In a retrospective study conducted by Yamaguchi et al., in which 600 patients with Meckel's diverticulum were included, 287 patients were symptomatic, with intestinal obstruction being the most common complication at $36.5 \%$, followed by intussusception at $13.7 \%$, diverticulitis $(12.7 \%)$, perforation $(7.3 \%)$, bleeding $(11.8 \%)$ and a diagnosis of neoplasm (3.2\%) [23].

Small bowel obstruction can develop following intussusception, with the diverticulum as a leading point, or when the diverticulae presents as an intraluminal polypoid mass [24].

Diagnosis of Meckel's diverticulum is usually difficult, and may result in late or missed diagnosis, thus; a high index of suspicion is always warranted, especially in patients presenting with complications of this rare entity [25]. Meckel's scan, also known as Technetium-99m Pertechnetate Scintigraphy, is the modality of choice for diagnosis, with a sensitivity of $85 \%$, a specificity of $95 \%$, and an overall accuracy of $90 \%$ in pediatric patients [26]. However, the diagnostic accuracy for the aforementioned modality is less than $50 \%$ in adult patients [27].

GI bleeding due to Meckel's diverticulum is usually the result of acid secretion from an ectopic mucosa, mostly gastric. This acidic secretion causes ulceration of the contralateral ileal wall mucosa. Other less common mechanism for GI bleeding is recurrent diverticular intussusception causing recurrent ileal mucosal erosion [10].

In the adult age group, bleeding due to Meckel's diverticulum is a very rare entity, and described as case reports in the English literature [28]. Heterotopic mucosa, mostly gastric, is found in almost $100 \%$ of patients with bleeding Meckel's diverticulum [12].

Lichstein et al., described a case of massive gastrointestinal bleeding originating from Meckel's diverticula in a 91-year-old male patient [29].

Due to its rare incidence in adult age group, there is no consensus on the surgical procedure of choice for symptomatic Meckel diverticulum and whether to resect an incidentally found diverticulae.

Regarding accidentally found Meckel's diverticulae, decision making for resection should be based on multiple risk factors for developing future complications. These factors include male sex, long diverticulae (more than $2 \mathrm{~cm}$, a presence of ectopic tissue and patients younger than 50 years of age. In these cases, a resection of the diverticulae should be done [30].

For symptomatic Meckel's diverticulum, definitive surgical resection is the treatment of choice. Surgical procedures include diverticulectomy, wedge resection or segmental resection. The type of surgical procedure depends usually on the presence and location of ectopic tissue and the integrity of the diverticular base and adjacent ileum [30]. 


\section{Conclusion}

Meckel's diverticulum, the most common GI congenital malformation, is a very rare entity encountered usually accidentally during operations for other pathologies. Due to its rare incidence in adult age group, a high index of suspicion is always warranted, especially in patients with obscure GI bleeding. In cases where diagnostic tools fail to point the source of the hemorrhage, patients should be prepared for a diagnostic laparoscopy or an exploratory laparotomy (depending on the urgency of the surgery and state of the patient), and Meckel's diverticula should be excluded during surgery.

\section{References}

1. Hilsden RJ, Shaffer EA. Management of gastrointestinal hemorrhage. Can Fam Physician. 1936; 41: 1939-1941. Ref.: https://bit.ly/2KnrPBn

2. Blatchford O, Davidson LA, Murray WR, Blatchford M, Pell J. Acute upper gastrointestinal haemorrhage in west of Scotland: case ascertainment study. BMJ. 1997; 315: 510-514. Ref.: https://bit.ly/2Xsa7A0

3. British Society of Gastroenterology Endoscopy Committee. Non-variceal upper gastrointestinal haemorrhage: guidelines. Gut. 2002; 4: 1-6. Ref.: https://bit.ly/2HS2cqJ

4. Bull-Henry K, Al-Kawas FH. Evaluation of occult gastrointestinal bleeding. Am Fam Physician. 2013; 87: 430-436. Ref.: https://bit.ly/2EOL1UR

5. Raju GS, Gerson L, Das A, Lewis B. American Gastroenterological Association (AGA) Institute medical position statement on obscure gastrointestinal bleeding. Gastroenterology. 2007; 133: 1694-1696. Ref.: https://bit.ly/30Yvqvn

6. Szold A, Katz LB, Lewis BS. Surgical approach to occult gastrointestinal bleeding. Am J Surg. 1992; 163: 90-92. Ref.: https://bit.ly/2Wht4sF

7. Gunjan D, Sharma V, Rana SS, Bhasin DK. Small bowel bleeding: a comprehensive review. Gastroenterology Report. 2014; 2: 262-275. Ref.: https://bit.ly/2EOt0pA

8. Zhang BL, Chen CX, Li YM. Capsule endoscopy examination. Identifies different leading causes of obscure gastrointestinal. Bleeding in patients of different ages. Turk J Gastroenterol. 2012; 23: 220 225. Ref.: https://bit.ly/2JROfN7

9. Levy AD, Hobbs CM. From the archives of the AFIP. Meckel diverticulum: radiologic features with pathologic correlation. Radiographics. 2004; 24: 565-587. Ref.: https://bit.ly/2XjTczA

10. Sagar J, Kumar V, Shah DK. Meckel's diverticulum: a systematic review. J R Soc Med. 2006; 99: 501505. Ref.: https://bit.ly/2WfAixF

11. Dumper J, Mackenzie S, Mitchell P, Sutherland F, Quan ML, et al. Complications of Meckel's diverticula in adults. Can J Surg. 2006; 49: 353-357. Ref.: https://bit.ly/2MIRNHM

12. Satya R, O'Malley JP. Meckel diverticulum with massive bleeding. Radiology. 2005; 236: 836-840. Ref.: https://bit.ly/2WyR9uB

13. Ymaguchi M, Takeuchi S, Awazu S. Meckel's diverticulum. Investigation of 600 patients in Japanese literature. Am J Surg. 1978; 136: 247-249. https://bit.ly/2JSHN71

14. Elsayes $\mathrm{KM}$, Menias $\mathrm{CO}$, Harvin HJ, Francis IR. Imaging manifestations of Meckel's diverticulum. AJR Am J Roentgenol. 2007; 189: 81-88. Ref.: https://bit.ly/2WfOW9C

15. Fink AM, Alexopoulou E, Carty H. Bleeding Meckel's diverticulum in infancy: unusual scintigraphic and ultrasound appearances. Pediatr Radiol. 1995; 25: 155-156 Ref.: https://bit.ly/310Y4vO

16. Stnescu GL, Pleșea IE, Diaconn R, Gheonea C, Sabetay C, et al. Meckel's diverticulum in children clinical and pathological aspects. Rom J Morphol Embryol. 2014; 55 (Supp 3): 1167-1170. Ref.: https://bit.ly/2loGNV9

17. Kusumoto $H$, Yoshida M, Takahashi I, Anai H, Maehara $Y$, et al. Complications and diagnosis of Meckel's diverticulum in 776 patients. Am J Surg. 1992; 164: 382-383. Ref.: https://bit.ly/2XjtThh

18. Stone PA, Hofeldt MJ, Campbell JE, Vedula G, DeLuca JA, et al. Meckel diverticulum: ten-year experience in adults. South Med J. 2004; 97: 1038-1041. Ref.: https://bit.ly/2lgztea

19. Mitchell AW, Spencer J, Allison DJ, Jackson JE. Meckel's diverticulum: angiographic findings in 16 patients. AJR. 1998; 170: 1329-1333. Ref.: https://bit.ly/2WG7Nly 
20. Carlioz P. Le diverticule de Meckel. De l'embryologie à la chirurgie. Montpellier: Sauramps. 2007. Ref.: https://bit.ly/2QBZ84F

21. Leijonmarck CE, Bonman-Sandelin K, Frisell J, Räf L. Meckel's diverticulum in the adult. Br J Surg. 1986; 73: 146-149. Ref.: https://bit.ly/2lcifyn

22. Chan KW, Lee KH, Mou JW, Cheung ST, Tam YH. Laparoscopic management of complicated Meckel's diverticulum in children: a 10-year review. Surg Endosc. 2008; 22: 1509-1512. Ref.: https://bit.ly/2YX4IBB

23. Yamaguchi M, Takeuchi S, Awazu S. Meckel's diverticulum. Investigation of 600 patients in Japanese literature. Am J Surg. 1978; 136: 247-249. Ref.: https://bit.ly/2JSHN71

24. Clark JK, Paz DA, Ghahremani GG. Imaging of Meckel's diverticulum in adults: pictorial essay. Clin Imaging. 2014; 38: 557-564. Ref.: https://bit.ly/2Wzqz4j

25. Lin S, Suhocki PV, Ludwig KA, Shetzline MA. Gastrointestinal bleeding in adult patients with Meckel's diverticulum: the role of technetium 99m pertechnetate scan. South Med J. 2002; 95: 1338-1341. Ref.: https://bit.ly/2HOnTaM

26. Sfakianakis GN, Conway JJ. Detection of ectopic gastric mucosa in Meckel's diverticulum and in other aberrations by scintigraphy: ii. Indications and methods-a 10-year experience. J Nucl Med. 1981; 22: 732-738. Ref.: https://bit.ly/2ldVxFX

27. Schwartz MJ, Lewis JH. Meckel's diverticulum: pitfalls in scintigraphic detection in the adult. Am J Gastroenterol. 1984; 79: 611-618. Ref.: https://bit.ly/2JPw3IG

28. Lee JS, Moon W, Park SJ, Park MI, Kim KJ, et al. Haemoorhagic Meckel's diverticulum in an older woman diagnosed by repeated angiographies. Turk J Gastroenterol. 2009; 20: 282-286. Ref.: https://bit.ly/2Xr1XBX

29. Lichtstein DM, Herskowitz B. Massive gastrointestinal bleeding from Meckel's diverticulum in a 91-year-old man. South Med J. 1998; 91: 753-754. Ref.: https://bit.ly/30S0jS6

30. Lequet J, Menahem B, Alves A, Fohlen A, Mulliri A. Meckel's diverticulum in the adult. J Visc Surg. 2017; 154: 253-259. Ref.: https://bit.ly/2HOh0q3 